\title{
Profitable Horizontal Mergers Without Efficiencies Can Increase Consumer Surplus*
}

\author{
Charles J. Thomas \\ Economic Science Institute \& Argyros School of Business and Economics \\ Chapman University
}

April 3, 2017

\begin{abstract}
In a simple model I show consumer surplus can increase after competing sellers consummate a profitable merger that generates no cost savings. This finding contrasts sharply with the conventional wisdom that horizontal mergers without efficiencies must enhance sellers' market power to be profitable, thereby harming buyers. The model fits industries in which individual buyers conduct distinct procurement contests for which sellers incur costs to participate, say to assess their product's fit with the buyer's preferences. Mergers benefit buyers by inducing stronger contest-level entry, echoing common claims from merging parties that their merger is beneficial because it creates a stronger competitor.
\end{abstract}

\section{Introduction}

The conventional wisdom in industrial organization theory and antitrust practice is that efficiencies are necessary for a profitable horizontal merger of rival sellers to benefit consumers. This view rests on the idea that if a merger's profitability does not arise from reducing the merging sellers' costs, then it must stem from increasing their market power. Increasing the sellers' market power harms buyers.

Analyses of mergers in standard oligopoly models used in antitrust provide theoretical support for the conventional wisdom. Perry and Porter (1985), Farrell and Shapiro (1990), and McAfee and Williams (1992) analyze Cournot models of quantity competition; the merging sellers reduce output postmerger, and their merger is profitable only if the non-merging sellers increase their output by a small enough amount that the market price increases sufficiently. Deneckere and Davidson (1985), Levy and Reitzes (1992), McElroy (1993), and Werden and Froeb (1994) analyze Bertrand models of price-setting with differentiated products; the merging sellers increase their prices postmerger, and their merger is profitable because the non-merging sellers likewise increase prices. Waehrer and Perry (2003) and Thomas (2004) respectively analyze models of second-price and first-price procurement auctions applicable to what competition authorities refer to as bidding markets, in which individual buyers conduct distinct procurement contests; ${ }^{1}$ in a second-price

*Email: charles.j.thomas.phd@gmail.com. For their generosity in inviting me to be an Affiliated Research Scientist, I thank Chapman University's Economic Science Institute \& Argyros School of Business and Economics. This work was completed in part while I was a Visiting Associate Professor at Clemson University's John E. Walker Department of Economics, whom I thank for their hospitality. Bill Dougan, Andy Hanssen, Mike Maloney, and Patrick Warren provided helpful advice.

Keywords: mergers, efficiencies, consumer surplus, antitrust

JEL: D4, D44, L1, L4

${ }^{1}$ Klemperer (2005) and OECD (2006) provide overviews of antitrust issues in bidding markets. 
auction the non-merging sellers do not change their prices following the merger, so the merger's only effect is to increase price and benefit the merging sellers when they would have placed first and second in the contest; in a first-price auction the merging sellers set a higher price, and their merger is profitable only if the non-merging sellers increase their prices sufficiently.

In this paper I demonstrate that the conventional wisdom can break down in bidding markets in which sellers incur costs to enter each procurement contest, say to assess their product's fit with the buyer's preferences or purchasing requirements, formulate an initial proposal, evaluate production costs, or design prototypes. Such costs are present in a variety of markets, including those for external audit services, highway construction, maintenance contracts, and hydroelectric power equipment. ${ }^{2}$ Similar costs are present in bidding markets in which bidders are buyers rather than sellers, such as in markets for oil or timber rights, radio spectrum, and large asset sales. ${ }^{3}$ French and McCormick (1984), McAfee and McMillan (1987), and Levin and Smith (1994) provide early theoretical analyses of the strategic impact of contest-level entry on outcomes in bidding markets. Thomas (2016) uses a model similar to the present one to address several antitrust policy issues affected by contest-level entry costs in bidding markets, but he makes a different assumption about postmerger contest-level entry costs that might be interpreted as reflecting efficiencies. ${ }^{4}$ The present paper unambiguously features no cost savings associated with a merger.

Evidence from merger investigations in several industries featuring bidding markets illustrates the empirical relevance of adding contest-level entry costs to a standard procurement model used in horizontal merger analysis. Table 1 lists mergers in which variation across contests in the participating sellers suggests contest-level entry costs are present.

Table 1. Industries and Mergers Exhibiting Contest-Level Entry Costs

\begin{tabular}{|l|l|l|}
\hline \multicolumn{1}{|c|}{ Industry } & \multicolumn{1}{|c|}{ Merger } & $\begin{array}{l}\text { European Commission } \\
\text { Case }\end{array}$ \\
\hline \hline railway transportation technology & Bombardier/ADtranz & COMP/M.2139 \\
\hline medical ventilators, anesthesia delivery systems & Siemens/Draegerwerk & COMP/M.2861 \\
\hline large turbines & Siemens/Alstom & COMP/M.3148 \\
\hline enterprise application software & Oracle/PeopleSoft & COMP/M.3216 \\
\hline supply of industrial gases & Air Liquide/Messer & COMP/M.3314 \\
\hline automotive components to OEMs & Magna/New Venture Gear & COMP/M.3486 \\
\hline equipment for hydroelectric power plants & Siemens/VA Tech & COMP/M.3653 \\
\hline professional mobile radio systems & EADS/Nokia & COMP/M.3803 \\
\hline secure plastic cards & Axalto/Gemplus & COMP/M.3998 \\
\hline equipment for mobile networks & Nokia/Siemens & COMP/M.4297 \\
\hline city buses & MAN/Scania & COMP/M.4336 \\
\hline
\end{tabular}

In bidding markets with contest-level entry costs, I show that a merger's profitability and effect on consumer surplus depend on the relative number of overlap contests (in which both merging sellers compete premerger) and non-overlap contests (in which only one merging seller competes premerger). In overlap

\footnotetext{
${ }^{2}$ Respectively, see Sullivan (2002), Krasnokutskaya and Seim (2011), Li and Zheng (2009), and OECD (2006).

${ }^{3}$ Respectively, see French and McCormick (1984), Athey, Levin, and Seira (2011), Binmore and Klemperer (2002), and Ye (2007).

${ }^{4} \mathrm{Li}$ and Zhang (2015) empirically assess hypothetical mergers in timber auctions in which entry costs appear to play a role, but they do not comprehensively assess what factors contribute to the merger effects they find in their merger simulations.
} 
contests the merging sellers gain and the buyer loses, for the same reason articulated by Waehrer and Perry (2003) in the standard model without contest-level entry costs: the merger's only effect is to increase price and benefit the merging sellers when they would have placed first and second in the contest. In non-overlap contests the merging sellers lose and the buyer gains, because the now-stronger merged seller enters the contest. That additional strength is worth less to the merged seller than it costs (otherwise the merging seller that does not compete premerger would find it profitable to do so), but it benefits the buyer by leading to lower prices. Importantly, in overlap contests the buyer's loss equals the merging sellers' gains, while in non-overlap contests the buyer's gain equals the non-merging sellers' losses and can easily outweigh the merging sellers' losses. Consequently, it is straightforward to construct scenarios with enough overlap contests so that the merger is profitable, but enough non-overlap contests so that the buyer benefits. In fact, I demonstrate that such mergers can exist if and only if the buyer's average gain across all non-overlap contests exceeds the merging sellers' average losses over all such contests.

Considering merger effects in different types of contests is a crucial departure from the papers supporting the conventional wisdom, which examine merger effects within a single market. If there were only a single type of contest in the bidding markets I consider, then either the merger would be profitable and reduce consumer surplus, or it would be unprofitable and increase consumer surplus. Presumably the latter type of mergers would not be proposed, so antitrust authorities could comfortably rely upon the conventional wisdom to conclude that proposed mergers without efficiencies harm buyers.

The mechanism by which profitable mergers without efficiencies can increase consumer surplus is consistent with the story frequently told by merging parties that their merger is beneficial because it will create a stronger competitor, and it illustrates an unusual force influencing a merger's effect; the buyer's gain in nonoverlap contests reflects a reduction in sellers' market power. Merger analysis typically weighs the negative effects of increased market power against the positive effects of efficiencies and new market-level entry, but does not consider that a merger might reduce market power. ${ }^{5,6}$ In the setting I consider the beneficial impact of reduced market power is reflected in the buyer's gain that comes at the non-merging sellers' expense.

Two other papers use different models to show the existence of horizontal mergers that increase consumer surplus in the absence of cost savings, but neither demonstrates that a merger of two sellers can simultaneously be profitable and increase consumer surplus in markets with more than two sellers. Stennek (2003) analyzes mergers in a Cournot duopoly in which sellers have private information about their constant marginal costs. A merger lets the sellers pool their cost information, leading to more efficient output decisions than occurred premerger when the sellers were uncertain about each other's costs. Those gains in efficiency can lead to lower expected prices for consumers, and in some cases can lead to higher expected consumer surplus. Shieh, Huang, and Chen (2013) analyze Cournot duopoly with differentiated products in which only one seller knows the true demand function. A merger lets both sellers know the true demand function, and the associated change in production can increase expected consumer surplus if demand is sufficiently volatile.

In the next section I introduce a simple procurement model with contest-level entry costs. Such simplicity is sufficient to demonstrate the existence of mergers that contradict the conventional wisdom, while it also facilitates a clear explanation of this surprising result's intuition.

\footnotetext{
${ }^{5}$ For example, see the Horizontal Merger Guidelines for the European Commission (2004) and the United States Department of Justice and Federal Trade Commission (2010).

${ }^{6}$ New market-level entry is not a factor in my analysis. Werden and Froeb (1998) argue that efficiencies and market-level entry are essentially the same issue, because "if a presumably profitable merger does not generate significant efficiences, it cannot be expected to induce entry." (p.525)
} 


\section{The Basic Procurement Model}

Consider $N \geq 2$ risk-neutral sellers who compete against each other in distinct procurement contests. An arbitrary contest $r$ is a competition to supply one unit of an indivisible good to a risk-neutral buyer who places the commonly-known value $v_{r}>0$ on having the contract fulfilled.

Competition in an arbitrary contest $r$ occurs in two stages whose structure is commonly known by the sellers. In the first stage the $N$ sellers simultaneously choose whether to sink the cost $e_{r} \geq 0$ to enter contest $r$. In the second stage the sellers observe which other sellers entered, then each seller privately learns its production cost for contest $r$ before the sellers make simultaneous price offers to the buyer. Seller $i$ 's cost $c_{i}$ is an independent draw from the differentiable cumulative distribution $F_{i, r}$ whose density is strictly positive on the interior of its support $\left[\underline{c}_{r}, \bar{c}_{r}\right]$, with $0 \leq \underline{c}_{r}<\bar{c}_{r} \leq v_{r}$.

The procurement contest's winner and transaction price are determined by second-price auction rules: the seller offering the lowest price wins if its price offer is less than or equal to $v_{r}$, and the transaction price paid to the winning seller is the smaller of the second-lowest price offer and $v_{r}$. If seller $i$ wins and the transaction price is $p$, then seller $i$ 's profit is $p-c_{i}$, all other sellers' profits are 0 , the buyer's profit is $v_{r}-p$, and total surplus is $v_{r}-c_{i}$. If the lowest price offer exceeds $v_{r}$, then no transaction occurs.

Modeling price competition as a second-price auction matches the approach taken in antitrust analyses of several industries, including retail pharmacy, timber rights, and software. ${ }^{7}$ The outcome of a secondprice auction also reflects the market-clearing outcome that is worst for the buyer, so in many settings a second-price auction might reasonably proxy for whatever mechanism determines transaction outcomes.

Variation across contests in $v_{r}, e_{r}$, and the $F_{i, r}$ would in practice reflect differences in the nature, size, or scope of the contracts being awarded. Such differences are noted in Section 4.1.4 of the US Horizontal Merger Guidelines, and they have been observed in antitrust analyses of industries such as the supply of medical imaging equipment (Philips/Agilent merger), perioperative patient monitors (GE/Instrumentarium merger), television audience measurement services (VNU/WPP merger), and satellites and satellite subsystems (Thales/Finmeccanica/AAS/Telespazio joint venture).$^{8}$

The sellers' equilibrium entry decisions in contest $r$ are based on the outcomes of post-entry price competition for each of the $2^{N}$ possible combinations of the $N$ sellers' entry decisions. Each set of entry choices leads to a subgame consisting of a set $A$ of active sellers who compete in the pricing stage.

The sellers' and the buyer's expected profits in a subgame are derived using the well known result in a second-price auction that each active seller has a dominant strategy to set its price equal to its cost. With multiple active sellers, active seller $i$ 's and the buyer's expected profits are

$$
\bar{\pi}_{i, r}^{A}=\int_{\underline{c}_{r}}^{\bar{c}_{r}}\left(\prod_{k \in A \backslash i}\left[1-F_{k, r}(c)\right]\right) F_{i, r}(c) d c-e_{r} \quad \text { and } \quad \bar{\pi}_{B, r}^{A}=\int_{\underline{c}_{r}}^{\bar{c}_{r}}\left(v_{r}-c\right) G_{(2: A), r}^{\prime}(c) d c,
$$

where $G_{(2: A), r}(c)$ is the cumulative distribution of the second-lowest cost draw from the set $A$ of active sellers:

$$
G_{(2: A), r}(c)=1-\left(\prod_{k \in A}\left[1-F_{k, r}(c)\right]\right)\left(1+\sum_{k \in A} \frac{F_{k, r}(c)}{1-F_{k, r}(c)}\right) .
$$

\footnotetext{
${ }^{7}$ Respectively, see Baker (1997), Brannman and Froeb (2000), and United States v. Oracle Corp., 331 F. Supp. 2d 1098 (N.D. Cal. 2004).

${ }^{8}$ Respectively, see European Commission cases COMP/M.2256, COMP/M.3083, COMP/M.3512, and COMP/M.4403.
} 
If seller $i$ is the only active seller, then it is paid $v_{r}$. Consequently, $\bar{\pi}_{i, r}^{A}=v_{r}-\int_{\underline{c}_{r}}^{\bar{c}_{r}} c F_{i, r}^{\prime}(c) d c-e_{r}$ and $\bar{\pi}_{B, r}^{A}=0$. If seller $i$ is inactive, then $\bar{\pi}_{i, r}^{A}=0$. With no active sellers, $\bar{\pi}_{B, r}^{A}=0$.

Based on the sellers' expected profits in each subgame associated with a possible combination of entry choices, the analyses by McAfee and McMillan (1987) and Levin and Smith (1994) of contest-level entry costs in symmetric models reveal there exist multiple equilibria that differ in sellers' entry choices. In symmetric models that have equilibria with randomization, McAfee and McMillan (1987) emphasize equilibria with deterministic entry decisions, all of which are asymmetric. By contrast, Levin and Smith (1994) emphasize symmetric equilibria with randomization by sellers in the entry stage. Analyses since Levin and Smith (1994) tend to use the symmetric mixed strategy equilibrium, because it is not clear to which asymmetric pure strategy equilibrium the players would gravitate.

Allowing for asymmetries across sellers reveals some subtleties when considering different entry equilibria, but I sidestep those by considering only equilibria in which sellers' entry probabilities weakly decrease as $e_{r}$ increases. Using this reasonable criterion, I still follow Levin and Smith (1994) by treating symmetric sellers identically, and if necessary I consider randomized entry decisions that do not violate monotonicity. This approach leads to a unique equilibrium of the 2-stage game, because arbitrarily asymmetric sellers drop out one at a time as $e_{r}$ increases. That is, each seller's entry probability equals 1 for a range of low $e_{r}$, then drops discontinuously and permanently to 0 once $e_{r}$ exceeds a threshold. Taking this approach is suitable because my goal is to demonstrate in a reasonable setting the existence of counterexamples to the conventional wisdom that profitable mergers without efficiencies must reduce consumer surplus.

\section{Assessing Merger Effects}

In this section I show how a merger without efficiencies can be profitable and increase expected consumer surplus, by modeling a horizontal merger of sellers $i$ and $j$ using a standard approach in the literature: Letting $M$ denote the merged seller, seller $M$ 's cost draw is the minimum of the cost draws of sellers $i$ and $j$. Waehrer (1999), Dalkir, Logan, and Masson (2000), Brannman and Froeb (2000), and Waehrer and Perry (2003) use this approach, which need not be interpreted literally as the merged seller keeping its members' production facilities. Rather, it reflects that the merger does not change the overall cost conditions of the two sellers jointly, in much the same way as the approach taken by Perry and Porter (1985) in the context of Cournot oligopoly. This structure's purpose is to emphasize the merger's strategic effects separately from any effects caused by cost changes in the market. The merged seller's cost distribution in contest $r$ is

$$
F_{M, r}(c)=1-\left[1-F_{i, r}(c)\right]\left[1-F_{j, r}(c)\right] .
$$

The crucial assumption I make about the merger is that seller $M$ learns it production cost by expending $2 e_{r}$. While other entry costs might also be reasonable, with this assumption it is unambiguous that the merger generates no cost savings for the merging sellers. ${ }^{9}$

Merger effects are straightforward to understand by considering how the merger changes the sellers' pricing behavior for particular realizations of their production costs. The non-merging sellers' prices in all contests equal their production costs, so they do not change their prices postmerger. Seller $M$ 's price in all contests is the smaller of the cost draws $c_{i}$ and $c_{j}$ from $F_{i, r}$ and $F_{j, r}$.

\footnotetext{
${ }^{9}$ Thomas (2016) assumes seller $M$ 's contest-level entry cost is $e_{r}$, a difference I alluded to earlier. That assumption might be viewed as an efficiency gain associated with the merger.
} 


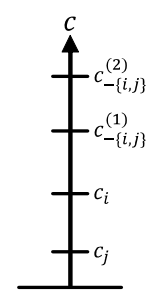

(a)

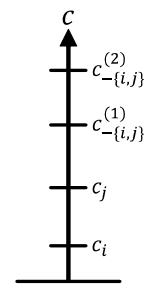

(b)

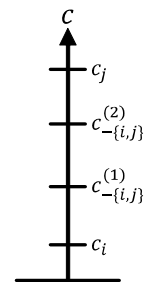

(c)

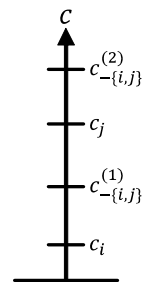

(d)

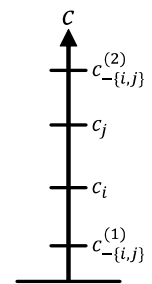

(e)

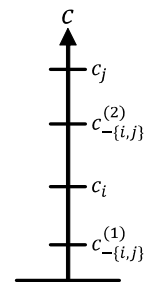

(f)

\begin{tabular}{|c|c|c|c|c|c|c|}
\hline \multicolumn{7}{|c|}{ Merger-Induced Changes in Profits in Overlap Contests } \\
\hline$\Delta \pi_{M, r}$ & $c_{-\{i, j\}}^{(1)}-c_{i}$ & $c_{-\{i, j\}}^{(1)}-c_{j}$ & 0 & 0 & 0 & 0 \\
\hline$\Delta \pi_{B, r}$ & $-\left(c_{-\{i, j\}}^{(1)}-c_{i}\right)$ & $-\left(c_{-\{i, j\}}^{(1)}-c_{j}\right)$ & 0 & 0 & 0 & 0 \\
\hline$\Delta \pi_{N M, r}$ & 0 & 0 & 0 & 0 & \multicolumn{2}{c|}{0} \\
\hline \multicolumn{7}{|c|}{ Merger-Induced Changes in Profits in Non-Overlap Contests } \\
\hline$\Delta \pi_{M, r}$ & 0 & $c_{j}-c_{i}$ & $c_{-\{i, j\}}^{(1)}-c_{i}$ & $c_{-\{i, j\}}^{(1)}-c_{i}$ & 0 & 0 \\
\hline$\Delta \pi_{B, r}$ & 0 & 0 & $c_{-\{i, j\}}^{(2)}-c_{-\{i, j\}}^{(1)}$ & $c_{j}-c_{-\{i, j\}}^{(1)}$ & $c_{j}-c_{i}$ & $c_{-\{i, j\}}^{(2)}-c_{i}$ \\
\hline$\Delta \pi_{N M, r}$ & 0 & 0 & $-\left(c_{-\{i, j\}}^{(2)}-c_{-\{i, j\}}^{(1)}\right)$ & $-\left(c_{j}-c_{-\{i, j\}}^{(1)}\right)$ & $-\left(c_{j}-c_{i}\right)$ & $-\left(c_{-\{i, j\}}^{(2)}-c_{i}\right)$ \\
\hline
\end{tabular}

Figure 1: Rank-Ordered Cost Realizations for which Merger of Sellers $i$ and $j$ Affects Profits

Figure 1 depicts the six rank-orderings of the sellers' realized production costs for which the merger affects at least one player's profit, revealing there are two relevant types of contests: overlap contests in which sellers $i$ and $j$ both enter premerger, and non-overlap contests in which seller $j$ enters premerger, but seller $i$ does not. The terms $c_{-\{i, j\}}^{(1)}$ and $c_{-\{i, j\}}^{(2)}$ denote the lowest and second-lowest cost realizations for active sellers other than $i$ and $j$. For each type of contest Figure 1 reports the change in the merging sellers' profits $\left(\Delta \pi_{M, r}\right)$, the buyer's profit $\left(\Delta \pi_{B, r}\right)$, and the non-merging sellers' aggregate profits $\left(\Delta \pi_{N M, r}\right)$.

Panels (a) and (b) in Figure 1 illustrate the only rank-orderings of cost realizations for which the merger affects any player's profit in overlap contests. Seller $M$ 's profit increases only when sellers $i$ and $j$ would have placed first and second premerger, because the price postmerger increases to the third-lowest of the active sellers' cost realizations (or to $v_{r}$ if there are no other active sellers). Moreover, the gain for seller $M$ also is the loss suffered by the buyer, who now pays the third-lowest cost rather than the second-lowest cost. The non-merging sellers' profits do not change, because each loses both premerger and postmerger.

Panels (b)-(f) in Figure 1 illustrate the only rank-orderings of cost realizations for which the merger affects any player's profit in non-overlap contests. Seller $M$ 's profit increases in panels (b)-(d), because in these cases seller $M$ continues to win but with a lower cost postmerger (panel (b)), or wins postmerger when it would have lost premerger (panels (c) and (d)). Notice that seller M's gains are exactly the profits that seller $i$ would have received if it entered the contest. Given that seller $i$ 's expected profit does not cover the contest-level entry cost $e_{r}$ in non-overlap contests (else seller $i$ would enter premerger), seller $M$ 's expected profit decreases in such contests. The buyer's profit increases in panels (c)-(f), because in those cases the price paid decreases. Moreover, the buyer's gains in those cases are exactly the losses incurred by the non-merging sellers. Those losses reflect either losing a contest postmerger the seller would have won premerger (panels (c) and (d)), or winning the contest premerger and postmerger, but at a lower price postmerger (panels (e) and (f)).

An example illustrates how a profitable merger without efficiencies can increase consumer surplus. Sup- 
pose in all contests that seller $i$ 's production $\operatorname{cost} c_{i}$ is an independent draw from the cumulative distribution

$$
F_{i}(c)=1-(1-c)^{t_{i}}
$$

where $t_{i}>0$ can be considered the "number" of draws seller $i$ takes from a distribution that is $U[0,1]$. Suppose there are four sellers, with $t_{1}=\frac{1}{3}, t_{2}=\frac{2}{3}, t_{3}=\frac{4}{3}, t_{4}=\frac{5}{3}$. Sellers with more cost draws are stronger than sellers with fewer cost draws, in the sense of having lower expected costs. They also have a higher probability of winning the contest, which is typically equated with their market share. ${ }^{10}$ Waehrer and Perry (2003) interpret $t_{i}$ as a measure of seller $i$ 's capacity in their analysis of second-price auctions with power distributions, of which the distribution $F_{i}$ is an example.

Table 2 reports premerger expected profits as a function of $e_{r}$, and to economize on space I list only the non-empty sets of active sellers that arise in equilibrium. For low values of $e_{r}$ all four sellers enter. Seller 1 stops entering when $e_{r}$ increases to 0.0143 , seller 2 stops entering when $e_{r}$ increases to 0.0357 , seller 3 stops entering when $e_{r}$ increases to 0.125 , and seller 4 stops entering when $e_{r}$ increases to $v_{r}-0.375$. For higher values of $e_{r}$ no sellers enter the procurement contest.

Table 2. Premerger Expected Profits for the Sellers and the Buyer

\begin{tabular}{|c|c|c|c|c|c|}
\hline$A$ & $\bar{\pi}_{1}^{A}$ & $\bar{\pi}_{2}^{A}$ & $\bar{\pi}_{3}^{A}$ & $\bar{\pi}_{4}^{A}$ & $\bar{\pi}_{B}^{A}$ \\
\hline \hline$\{1,2,3,4\}$ & $0.0143-e_{r}$ & $0.0308-e_{r}$ & $0.0727-e_{r}$ & $0.1-e_{r}$ & $v_{r}-0.4178$ \\
\hline$\{2,3,4\}$ & 0 & $0.0357-e_{r}$ & $0.0857-e_{r}$ & $0.119-e_{r}$ & $v_{r}-0.4548$ \\
\hline$\{3,4\}$ & 0 & 0 & $0.125-e_{r}$ & $0.1786-e_{r}$ & $v_{r}-0.5536$ \\
\hline$\{4\}$ & 0 & 0 & 0 & $v_{r}-0.375-e_{r}$ & 0 \\
\hline
\end{tabular}

A merger of sellers 1 and 2 combines the two smallest of the four sellers, and the merged seller remains the smallest $\left(t_{M}=1<t_{3}<t_{4}\right)$. Table 3 reports postmerger expected profits as a function of $e_{r}$, again listing only the non-empty sets of active sellers that arise in equilibrium.

Table 3. Postmerger Expected Profits for the Sellers and the Buyer

\begin{tabular}{|c|c|c|c|c|}
\hline$A$ & $\bar{\pi}_{M}^{A}$ & $\bar{\pi}_{3}^{A}$ & $\bar{\pi}_{4}^{A}$ & $\bar{\pi}_{B}^{A}$ \\
\hline \hline$\{M, 3,4\}$ & $0.05-2 e_{r}$ & $0.0727-e_{r}$ & $0.1-e_{r}$ & $v_{r}-0.4227$ \\
\hline$\{3,4\}$ & 0 & $0.125-e_{r}$ & $0.1786-e_{r}$ & $v_{r}-0.5536$ \\
\hline$\{4\}$ & 0 & 0 & $v_{r}-0.375-e_{r}$ & 0 \\
\hline
\end{tabular}

Contests with $e_{r}<0.0143$ are overlap contests. The merging sellers' expected profits increase by 0.0049 , the buyer's expected profit decreases by 0.0049 , and the non-merging sellers' expected profits do not change.

Contests with $0.0143<e_{r}<0.0357$ are non-overlap contests in which seller 2 enters premerger but seller 1 does not. The merging sellers' expected profits decrease by $e_{r}-0.0143$, the buyer's expected profit increases by 0.032 , and the non-merging sellers' expected profits decrease by 0.032 .

Contests with $e_{r}>0.0357$ are non-overlap contests in which sellers 1 and 2 both are inactive premerger, and seller $M$ is inactive postmerger. The merger has no effect on any player's expected profit.

To see how profitable mergers without efficiencies can increase consumer surplus, suppose a particular market consists of only two types of contests. A fraction $\alpha^{O}$ of all contests are overlap contests in which sellers 1 and 2 both compete premerger; the associated contest-level entry cost is $e^{O} \in(0,0.0143)$. The remaining fraction $1-\alpha^{O}$ of all contests are non-overlap contests in which seller 2 competes premerger, but seller 1 does not; the associated contest-level entry cost is $e^{N} \in(0.0143,0.0357)$.

\footnotetext{
${ }^{10}$ For example, see Dalkir, Logan, and Masson (2000) and Waehrer and Perry (2003).
} 
Merger profitability requires the merging sellers' expected gains in overlap contests to outweigh their expected losses in non-overlap contests, so the average effect per contest must be such that

$$
\alpha^{O}(0.0049)+\left(1-\alpha^{O}\right)\left(0.0143-e^{N}\right)>0 \Longleftrightarrow \alpha^{O}>\frac{e^{N}-0.0143}{e^{N}-0.0094} .
$$

The intuition for needing $\alpha^{O}$ sufficiently high is that there must be enough overlap contests, because they are where the merging sellers experience gains.

Increasing expected consumer surplus requires the buyer's expected loss in overlap contests to be outweighed by its expected gain in non-overlap contests, so the average effect per contest must be such that

$$
\alpha^{O}(-0.0049)+\left(1-\alpha^{O}\right)(0.032)>0 \Longleftrightarrow \alpha^{O}<0.8672 \text {. }
$$

The intuition for needing $\alpha^{O}$ sufficiently low is that there must be enough non-overlap contests, because they are where the buyer experiences gains.

There are several ways to compare the preceding two conditions, but first notice that the contest-level entry cost $e^{O}$ for the overlap contests is irrelevant to the existence of profitable mergers without efficiencies that increase consumer surplus; the merging sellers' expected gains in overlap contests, and therefore the buyer's expected loss, are unaffected by the cost $2 e^{O}$ the merging sellers incur both premerger and postmerger.

One way to compare the two conditions is to let $e^{N}$ approach 0.0143 from above, recalling that $e^{N} \in$ $(0.0143,0.0357)$. This case reflects the best non-overlap contests from the merging sellers' perspective, in the sense that seller $M$ 's losses in the non-overlap contests are vanishingly small. The merger is profitable and increases expected consumer surplus when $0<\alpha^{O}<0.8672$.

Alternatively, one can fix $e^{N}$ at an intermediate level and determine the relevant range of $\alpha^{O}$. For example, if $e^{N}=0.02$, then the merger is profitable and increases expected consumer surplus when $0.5377<$ $\alpha^{O}<0.8672$. Obviously, as the merging sellers' losses in the non-overlap contests increase, a larger fraction of overlap contests are necessary for the merger to be profitable.

Finally, there can exist $\alpha^{O}$ that satisfy both conditions if and only if

$$
\frac{e^{N}-0.0143}{e^{N}-0.0094}<0.8672 \Longleftrightarrow e^{N}<0.0463
$$

Given that $e^{N} \in(0.0143,0.0357)$ for non-overlap contests in which seller 2 enters premerger but seller 1 does not, the preceding condition reveals that in this example there always exists the possibility of a profitable merger without efficiencies that increases consumer surplus.

Two factors that complicate the analysis of merger effects relate to how a merger can change entry behavior. First, if $e^{N} \in(0.025,0.0357)$ in the example presented above, then seller $M$ will not enter the non-overlap contest that seller 2 would have entered premerger. This loss in competition from seller 2 harms the buyer postmerger. Second, a merger might cause one or more non-merging sellers not to enter a contest they would have entered premerger. This can occur in non-overlap contests if seller $M$ is sufficiently stronger than was the sole merging seller who would have entered premerger. This change in entry behavior might be harmful to the buyer.

Figure 1 and the preceding example illuminate a path toward a general assessment of when there can exist profitable mergers without efficiencies that increase consumer surplus. For a merger of arbitrary sellers 
$i$ and $j$, and using the same definitions of overlap and non-overlap contests as above, for $X, Y, Z>0$ let

$$
\begin{aligned}
& X \equiv \text { the average increase in the merging sellers' expected profits in overlap contests } \\
& X \equiv \text { the average decrease in the buyer's expected profit in overlap contests } \\
& Y \equiv \text { the average decrease in the merging sellers' expected profits in non-overlap contests } \\
& Z \equiv \text { the average increase in the buyer's expected profit in non-overlap contests. }
\end{aligned}
$$

It is important to recognize that the definitions of $X, Y$, and $Z$ do not require the preceding example's assumptions that all overlap contests are the same and that all non-overlap contests are the same. Instead, $X$ can represent the increase in the merging sellers' expected profits averaged over a whole host of overlap contests that vary in $v_{r}, e_{r}$, all $N$ sellers' cost distributions, and the associated number and identities of active sellers. Likewise, $Y$ and $Z$ can represent broadly interpreted changes in expected profits averaged over all non-overlap contests in which only one of the merging sellers enters premerger.

Again letting $\alpha^{O}$ denote the frequency of overlap contests, merger profitability requires that

$$
\alpha^{O}(X)+\left(1-\alpha^{O}\right)(-Y)>0 \Longleftrightarrow \alpha^{O}>\frac{Y}{X+Y}
$$

Increasing expected consumer surplus requires that

$$
\alpha^{O}(-X)+\left(1-\alpha^{O}\right)(Z)>0 \Longleftrightarrow \alpha^{O}<\frac{Z}{X+Z} .
$$

There exists $\alpha^{O}$ satisfying the two preceding constraints if and only if

$$
\frac{Y}{X+Y}<\frac{Z}{X+Z} \Longleftrightarrow Y<Z
$$

Therefore, the possibility of profitable mergers without efficiencies that increase expected consumer surplus requires only that in non-overlap contests the average increase in the buyer's expected profit $(Z)$ exceeds the average decrease in the merging sellers' expected profits $(Y)$.

Notice that the preceding condition accounts for the two complicating factors regarding changed entry behavior that were mentioned after the four-seller example. Even if in some non-overlap contests the merger leads to changes in entry patterns that harm the buyer, $Z$ is the average over all non-overlap contests. If $Z$ is negative because of postmerger changes in entry patterns, then there cannot be profitable mergers that increase expected consumer surplus. However, the presence of a few non-overlap contests in which the buyer's expected profit falls does not imply the buyer cannot see its expected profits increase on average.

\section{Conclusion}

In a simple model I demonstrate that consumer surplus can increase after competing sellers consummate a profitable merger that generates no cost savings. The mechanism generating this unexpected result echoes common claims from merging parties that their merger is beneficial because it will make them a stronger competitor: when contest-level entry costs matter, a horizontal merger can lead to stronger entry by the merged seller into contests that one of the merging sellers would have avoided premerger. The gains in consumer surplus in such contests can easily outweigh the losses in consumer surplus in overlap contests. In 
fact, I show that profitable horizontal mergers without efficiencies that increase consumer surplus can exist if and only if the increase in the buyer's expected profit across all non-overlap contests exceeds the decrease in the merging sellers' expected profits across all such contests.

The existence of such mergers contrasts with the conventional wisdom that if a horizontal merger without efficiencies is profitable, then the source of profitability must be increased market power that harms buyers. While care must be taken to balance a merger's positive and negative effects across different contests or buyers, the more fundamental point demonstrated here is that accounting for contest-level entry costs can provide a simple and reasonable counterexample to a widely held view about horizontal mergers. Such costs' empirical relevance is evident from the variety of merger investigations that find substantial variation in sellers' participation across contests in an industry, such as Alcatel/Lucent Technology (telecommunication technology), Metso/Aker Kvaerner (equipment for chemical pulp mills), CommScope/Andrew (coaxial cable), Syniverse/BSG (data clearing services for Mobile Network Operators), EADS/SSTL (civil institutional satellites), ${ }^{11}$ and the many other merger cases cited in the paper.

My finding relies upon evaluating merger effects across different types of contests. This approach is crucial, because theoretical analyses that support the conventional wisdom look within a single market, say as embodied in a particular demand system or a single auction.

In closing it is worth mentioning that my finding based on contest-level entry might be applicable beyond the confines of bidding markets, such as in R\&D-intensive industries. For example, not every pharmaceutical company attempts to develop treatments for every ailment. Such R\&D "contests" seem conceptually similar to the bidding markets I analyze, including the notion of overlap and non-overlap contests. Mergers that bring otherwise-unused capabilities to bear on a particular stream of research presumably can have positive effects like those in the model I analyze.

\section{References}

[1] Athey, S., Levin, J., and Seira, E. (2011) "Comparing Open and Sealed Bid Auctions: Evidence from Timber Auctions." Quarterly Journal of Economics 126, 207-257.

[2] Baker, J. B. (1997). "Unilateral Competitive Effects Theories in Merger Analysis." Antitrust 11(2), $21-26$.

[3] Binmore, K., and Klemperer, P. (2002). "The Biggest Auction Ever: the Sale of the British 3G Telecom Licences." The Economic Journal 112(478), C74-C96.

[4] Brannman, L., and Froeb, L. (2000). "Mergers, Cartels, Set-Asides, and Bidding Preferences in Asymmetric Oral Auctions." Review of Economics and Statistics 82(2), 283-290.

[5] Dalkir, S., Logan, J., and Masson, R. (2000). "Mergers in Symmetric and Asymmetric Noncooperative Auction Markets: the Effects on Prices and Efficiency." International Journal of Industrial Organization 18(3), 383-413.

[6] Deneckere, R., and Davidson, C. (1985). "Incentives to Form Coalitions with Bertrand Competition." RAND Journal of Economics 16(4), 473-486.

\footnotetext{
${ }^{11}$ Respectively, see European Commission cases COMP/M.4214, COMP/M.4187, COMP/M.4819, COMP/M.4662, and COMP/M.5168.
} 
[7] European Commission (2004). "Guidelines on the Assessment of Horizontal Mergers Under the Council Regulation on the Control of Concentrations Between Undertakings." Official Journal of the European Union C 31, 5-18. (http://eur-lex.europa.eu/legal-content/EN/ALL/?uri=CELEX:52004XC0205(02)).

[8] Farrell, J., and Shapiro, C. (1990). "Horizontal Mergers: An Equilibrium Analysis." American Economic Review 80(1), 107-126.

[9] French, K., and McCormick, R. (1984). "Sealed Bids, Sunk Costs, and the Process of Competition." The Journal of Business 57(4), 417-441.

[10] Klemperer, P. (2005). "Bidding Markets." Occasional Paper No. 1, U.K. Competition Commission.

[11] Krasnokutskaya, E., and Seim, K. (2011). "Bid Preference Programs and Participation in Highway Procurement Auctions." American Economic Review 101, 2653-2686.

[12] Levin, D., and Smith, J. (1994). "Equilibrium in Auctions with Entry." American Economic Review $84(3), 585-599$.

[13] Levy, D., and Reitzes, J. (1992). "Anticompetitive Effects of Mergers in Markets with Localized Competition." Journal of Law, Economics, \& Organization 8(2), 427-440.

[14] Li, T., and Zhang, B. (2015). "Affiliation and Entry in First-Price Auctions with Heterogeneous Bidders: An Analysis of Merger Effects." American Economic Journal: Microeconomics 7(2), 188-214.

[15] Li, T., and Zheng, X. (2009). "Entry and Competition Effects in First-Price Auctions: Theory and Evidence from Procurement Auctions." Review of Economic Studies 76, 1397-1429.

[16] McAfee, R.P., and McMillan, J. (1987). "Auctions with Entry." Economics Letters 23, 343-347.

[17] McAfee, R.P., and Williams, M. (1992). "Horizontal Mergers and Antitrust Policy." Journal of Industrial Economics 40(2), 181-187.

[18] McElroy, F. (1993). "The Effects of Mergers in Markets for Differentiated Products." Review of Industrial Organization 8, 69-81.

[19] OECD (2006). "Policy Roundtable: Competition in Bidding Markets." DAF/COMP(2006)31.

[20] Perry, M.K., and Porter, R. (1985). "Oligopoly and the Incentive for Horizontal Merger." American Economic Review 75(1), 219-227.

[21] Shieh, S., Huang, C., and Chen, H.C. (2013). "Can Horizontal Mergers without Synergies Increase Consumer Welfare? Cournot and Bertrand Competition Under Uncertain Demand." The B.E. Journals in Economic Analysis 83 Policy 13(1), 453-484.

[22] Stennek, J. (2003). "Horizontal Mergers without Synergies May Increase Consumer Surplus." The B.E. Journals in Economic Analysis 8 Policy 3(1), Article 2.

[23] Sullivan, M. (2002). "The Effect of the Big Eight Accounting Firm Mergers on the Market for Audit Services." Journal of Law and Economics 45(2), 375-399.

[24] Thomas, C.J. (2004). "The Competitive Effects of Mergers Between Asymmetric Firms." International Journal of Industrial Organization 22(5), 679-692. 
[25] Thomas, C.J. (2016). "A New Perspective on Entry in Horizontal Merger Analysis." working paper.

[26] U.S. Department of Justice, and Federal Trade Commission (2010). "Horizontal Merger Guidelines." (http://www.ftc.gov/sites/default/files/attachments/merger-review/100819hmg.pdf).

[27] Waehrer, K. (1999). "Asymmetric Private Values Auctions with Application to Joint Bidding and Mergers." International Journal of Industrial Organization 17, 437-452.

[28] Waehrer, K., and Perry, M. (2003). "The Effects of Mergers in Open-Auction Markets." RAND Journal of Economics 34(2), 287-304.

[29] Werden, G., and Froeb, L. (1994). "The Effects of Mergers in Differentiated Products Industries: Logit Demand and Merger Policy." Journal of Law, Economics, \&3 Organization 10(2), 407-426.

[30] Werden, G., and Froeb, L. (1998). "The Entry-Inducing Effects of Horizontal Mergers: An Exploratory Analysis." Journal of Industrial Economics 46(4), 525-543.

[31] Ye, L. (2007). "Indicative Bidding and a Theory of Two-Stage Auctions." Games and Economic Behavior $58,181-207$. 